\title{
Finite Element Analysis of Thermoelectric Generator with Aluminum Plate for Waste Heat Recovery Application
}

\author{
Muhammad Nubli Zulkifli", Izzudin Ilias", Amir Abas ${ }^{*}$, Wan Mansor Wan Muhamad ${ }^{1}$ \\ ${ }^{\#}$ Universiti Kuala Lumpur (UniKL), International College (ICOLE), British Malaysia Institute (BMI), Jalan Sungai Pusu, 53100 Gombak, \\ Selangor, Malaysia \\ E-mail:mnubliz@unikl.edu.my;din_ilias@ymail.com \\ *Universiti Kuala Lumpur (UniKL), British Malaysia Institute (BMI), Electronic Technology Section, Jalan Sungai Pusu, 53100 Gombak, \\ Selangor, Malaysia \\ E-mail:drmamir@unikl.edu.my \\ ${ }^{1}$ Universiti Kuala Lumpur (UniKL), International College (ICOLE), Malaysian France Institute (MFI), Section 14, Jalan Teras Jernang, \\ Bandar Baru Bangi, 43650 Bandar Baru Bangi, Selangor, Malaysia \\ E-mail:drwmansor@unikl.edu.my
}

\begin{abstract}
Thermoelectric generator (TEG) is the solid state device that converts the thermal gradient into electrical energy. TEG is widely used as the renewable energy source especially for the electronic equipment that operates with the small amount of electrical power. In the present analysis, the finite element analysis (FEA) using ANSYS is conducted on a model of the TEG attached with the aluminium, Al plate on the hot side of the TEG. This simple construction of TEG model was built in order to be used in the waste heat recovery application. It was shown that the changes of the width and thickness of the Al plate increased the temperature gradient between hot and cold sides of TEG. This directly increase the voltage produced by the TEG based on the Seeback effect. The increase of the thermal gradient due to the increment of thickness and width of Al plate might be because of the increase of thermal resistance of Al plate. Based on statistical analysis using full factorial of design of experiment, Al thickness play a major role in changing the performance of proposed TEG compared to that of $\mathrm{Al}$ width. This finding provides a valuable data in design process to build a good TEG attached with Al plate for the waste heat recovery application.
\end{abstract}

Keywords - Thermoelectric generator; Finite Element Analysis; Energy Harvester; Full Factorial; Renewable Energy

\section{INTRODUCTION}

The pollution issues have increased the concern of using the environmental friendly power generation [1],[2]. Waste heat recovery using thermoelectric material is one of the environmental friendly power generators that widely used nowadays. Thermoelectric power generator have been used to recover waste heat from different type of sources such as heat dissipation from vehicles, sun irradiation, hot waste water from industry to name a few. Thermoelectric power generation only requires the thermal gradient to generate the electrical energy and do not produces any additional polluted by-products. Thermoelectric power generator is operated due to the Seeback effect where the generation of electrical potential is directly proportionate with the gradient of temperature between the hot and cold sides of thermoelectric material [3].

There are some studies have been conducted to utilise the thermoelectric generator (TEG) in order to generate the electrical power. Waste heat recovery from the cars [4]-[6], hot water or hot gas wastage from industries [7],[8], heat from the sun irradiance or as part of hybrid system with other power generator devices [9]-[11] are some of the application of the TEG to name a few.

Finite element analysis (FEA) is one of the methods that has been widely used to design and optimize the TEG in the earlier stage before the development process. This provides an initial result in order to develop an optimized prototype of TEG right before it is tested in the field. Some researchers have successfully carried out the FEA in order to design and build the prototype of TEG devices [12]-[16]. Antonova and Looman [12] reported the procedure of conducting FEA on 
TEG model using ANSYS and also the possible solution in the process of designing the TEG. Chen et al. [13] conducted a numerical analysis or FEA on the TEG with thermalconcentrated solar panel. They noted that the thermal resistance and thermal spreading resistance of thermalconcentrated solar panel are two major factors affecting the performance of TEG. Clin et al. [14] carried out thermomechanical analysis on the extruded bismuth telluride (BiTe) using FEA and found that thermal changes has significant effect on changing the deformation behavior of TEG module. Crane et al. [15] conducted steady state and transient analyses using FEA on the cylindrical TEG that usually used for the waste recovery for gas and liquid. They reported that the prototype of cylindrical TEG was based on the optimization process conducted through FEA. Kossyvakis et al. [16] reported that FEA can be used to evaluate and validate the commercial available TEG performance with a good agreement.

In the current study, simulation of simple construction of TEG is carried out by using commercial FEA software, ANSYS. A three dimensional (3D) model of TEG that consist of n-type and p-type bismuth telluride alloys, copper strip, alumina or ceramic plate and also aluminum plate are built to analyse the deterministic behavior of the TEG. The thickness and width of aluminum plate are chosen as the design variables or the factors of interest for the proposed TEG model. Statistical analysis using design of experiment (DOE) of full factorial is conducted in order to analyse the effect of selected factors (Al thickness and width) on the performance of TEG based on the value of heat rate, electrical power and output power.

\section{MATERIAL \& METHOD}

The built-in tool in ANSYS named Parametric Design Language and Macros (APDL) is used to execute the FEA program in ANSYS. A three dimensional (3D) model of TEG that consist of n-type and p-type bismuth telluride (BiTe) alloys, copper $(\mathrm{Cu})$ strip, alumina $\left(\mathrm{Al}_{2} \mathrm{O}_{3}\right)$ or ceramic plate and also aluminum ( $\mathrm{Al})$ plate is built as a model for the FEA. The TEG is connected in series electrically and parallel thermally. The material and element definitions and also the coupled-field analysis for TEG are based on studies of Antonova and Looman [12] and Erturun et al. [17]. Table 1 shows the geometry and materials definition for the TEG. Figure 1 illustrates the model and material used for the TEG.

TABLE 1

GEOMETRY AND MATERIALS DEFINITION FOR THE TEG

\begin{tabular}{|lccccc|}
\hline \multicolumn{1}{|c}{ Material Definition and Geometry } & $\mathbf{A l}$ & $\begin{array}{c}\mathbf{A l}_{\mathbf{2}} \mathbf{O}_{\mathbf{3}}, \\
\mathbf{C e r a m i c}\end{array}$ & $\mathbf{C u}$ & n-type BiTe & p-type BiTe \\
\hline Electrical Resistivity, $\rho(\mu \Omega \mathrm{m})$ & 0.25 & $1 \times 10^{18}$ & $0.18-0.38$ & $9.8-14.9(300-$ & $13.8-25.0$ \\
& & & $(300-600 \mathrm{~K})$ & $500 \mathrm{k})$ & $(300-500 \mathrm{~K})$ \\
Thermal Conductivity, $\lambda(\mathrm{W} / \mathrm{Mk})$ & 200 & $37.2-17.2$ & $398-382$ & $1.78-3.50$ & $1.22-5.24$ \\
& & $(293-600 \mathrm{~K})$ & $(293-600 \mathrm{~K})$ & $(300-500 \mathrm{~K})$ & $(300-500 \mathrm{~K})$ \\
Seeback Coefficient, $\alpha\left(10^{-6} / \mathrm{K}\right)$ & - & - & - & 16.8 & 16.8 \\
Thickness $(\mathrm{cm})$ & 0.50 & 0.05 & 0.075 & 1.00 & 1.00 \\
Length $(\mathrm{cm})$ & 1.00 & 1.00 & 1.00 & 1.00 & 1.00 \\
Width $(\mathrm{cm})$ & 3.14 & 2.64 & 1.00 & 1.00 & 1.24 \\
\hline
\end{tabular}

The element of SOLID226 is selected for all materials because it has three isoparametric couple-field elements with structural, thermal, and electrical degrees of freedom at nodes. Present analysis is called as coupled-field analysis due to the combined analysis between thermal and electric (thermoelectric) fields. ANSYS has the capability in order to conduct the thermoelectrical analysis and it has been successfully applied by several researches [12],[14],[17],[18]. Figure 1 shows the model developed for the proposed TEG. From Figure 1, the Al plate is placed on the top of the hot side of TEG. The configuration in Figure 1 also shows that the connection for TEG is electrically in series with the cold side TEG connected to an external resistance of $R_{o}$, and thermally in parallel with the hot side is on top and cold side is at the bottom of TEG.

To conduct the thermoelectric analysis, several governing equations should be taken into consideration. Following are the conduction and continuity equations for the coupled equations of thermoelectricity [17].

$$
\nabla \cdot(\alpha T \vec{J})-\nabla \cdot(\mathrm{k} \nabla T)=\vec{J} \cdot \vec{E}
$$

$$
\nabla \cdot\left(\frac{1}{\rho_{e}} \vec{E}\right)-\nabla \cdot\left(\frac{\alpha}{\rho_{e}} \nabla T\right)=0
$$

where $T$ and $\vec{E}$ represent the temperature and the electric field, respectively. The electric field is derived from the electric scalar potential $\phi(\vec{E}=-\nabla \phi) ; \vec{J}$ represents the electric current density vector. $\alpha, k$, and $\rho_{e}$ represent the Seeback coefficient, thermal conductivity, and the electrical resistivity of thermoelectric element, respectively.

The steady-state analysis is performed to analyse the temperature distribution and power generation of TEG. The temperature gradient of $300{ }^{\circ} \mathrm{C}$ for steady-state analysis is applied between the hot and cold sides of TEG. Steady state analysis is carried by assigning the hot temperature of $327^{\circ} \mathrm{C}$ on the top of the Al plate and cold temperature of $27{ }^{\circ} \mathrm{C}$ on the bottom side of $\mathrm{Al}_{2} \mathrm{O}_{3}$ ceramic side that located near the cold side TEG. This creates $300{ }^{\circ} \mathrm{C}$ of temperature gradient between the hot side and the cold side of TEG. The power generation analysis is conducted by measuring several parameters namely electrical current, $I$ output power, $P$ and efficiency, $\eta$ as follows [12]: 


$$
\begin{aligned}
& I=\frac{\alpha \Delta T}{R+R_{o}} \\
& P_{o}=I^{2} R_{o} \\
& \eta=\frac{P_{o}}{Q_{h}}
\end{aligned}
$$

where $\Delta T$ is the temperature gradient between the hot and cold sides of thermoelectric material, $R$ is the combined internal electrical resistance for the $\mathrm{p}$ - and n-type thermoelectric legs, $R_{o}$ is the external resistance, and $Q_{h}$ is the thermal input to the hot junction or heat rate.

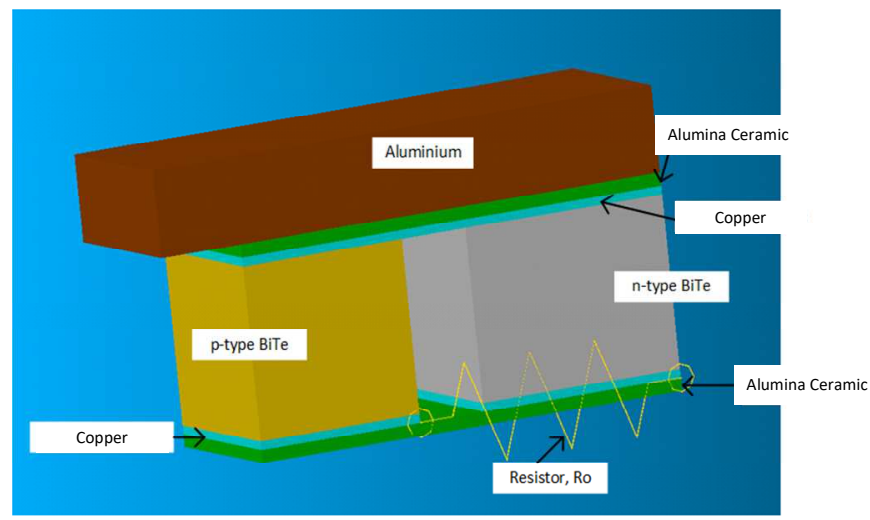

Fig. 1 Model of TEG

Design of experiment (DOE) using full factorial is used to analyse the effect of selected factors namely the thickness and the width of Al plate on the performance of TEG. Table 2 shows the design sets based on the full factorial for FEA of TEG.

TABLE 2

DESIGN SETS BASED ON FULL FACTORIAL FOR FEA OF

\begin{tabular}{ccc} 
& TEG & \\
\hline \multirow{2}{*}{ Design Sets } & $\begin{array}{c}\text { Al Plate } \\
\text { Thickness }(\mathbf{c m})\end{array}$ & $\begin{array}{c}\text { Al Plate Width } \\
(\mathbf{c m})\end{array}$ \\
\hline 1 & 0.50 & 0.50 \\
2 & 0.50 & 10.00 \\
3 & 10.00 & 0.50 \\
4 & 10.00 & 10.00 \\
\hline
\end{tabular}

\section{RESULTS AND DISCUSSION}

Figure 2 illustrates thermal distribution of TEG for each design sets 1, 2, 3, and 4. In Figure 2, it is indicated that the hot side of TEG experiences the highest temperature, whereas the cold side of TEG experiences the lowest temperature of heat. This is in agreement with the temperature loads assigned earlier where the highest temperature is applied at the hot side of TEG, and the lowest temperature is applied at the cold side of TEG. However, there is the drop of temperature between the $\mathrm{Al}$ plate and the hot side of TEG with value of $325.440{ }^{\circ} \mathrm{C}, 325.445{ }^{\circ} \mathrm{C}$, $309.637{ }^{\circ} \mathrm{C}$, and $318.165{ }^{\circ} \mathrm{C}$ for design sets $1,2,3$, and 4 , respectively. The purpose of putting the alumina ceramic on top and bottom side of TEG is to give a support and also to increase the rigidity of TEG. This is because the thermoelectric material or BiTe alloy is brittle and easily crack.

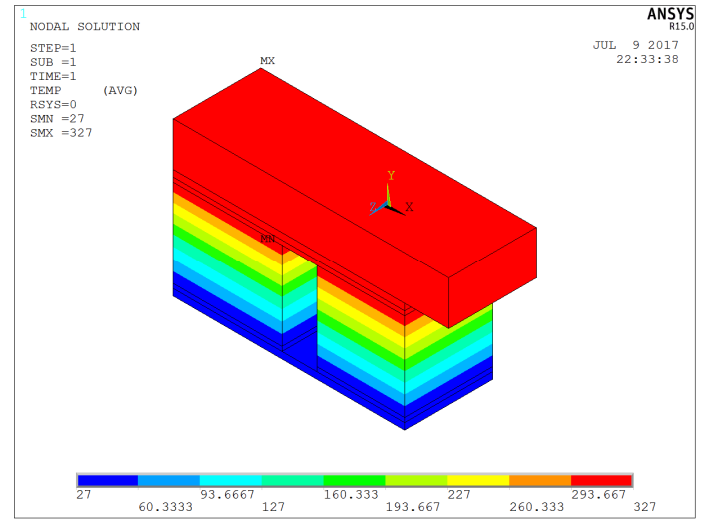

(a)

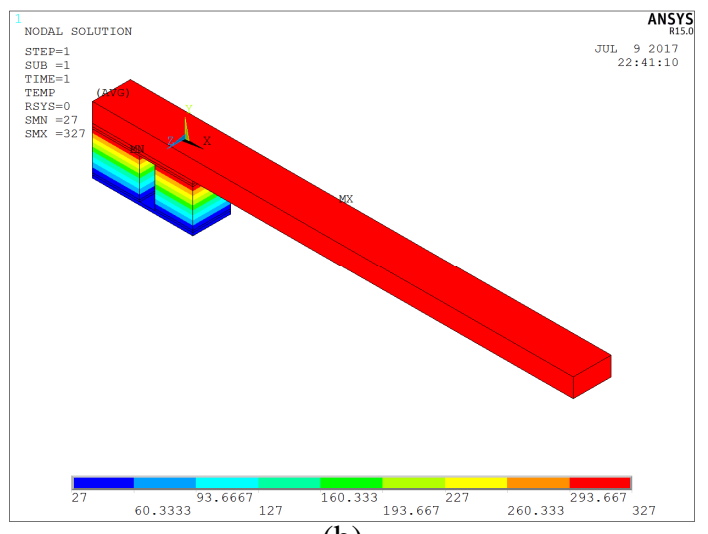

(b)

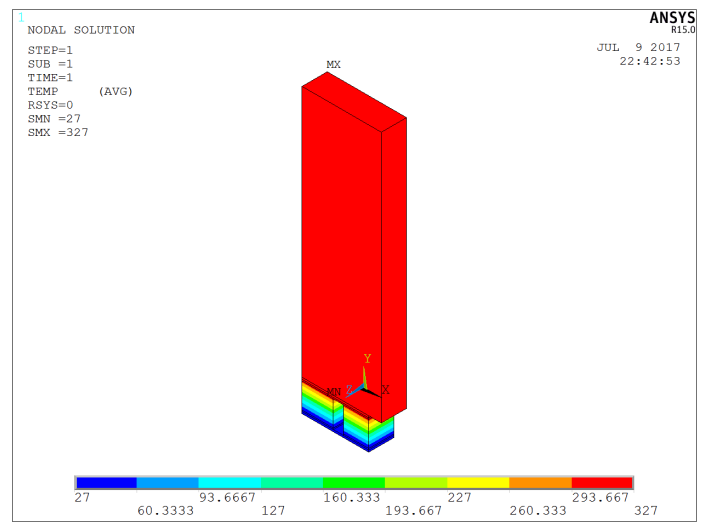

(c)

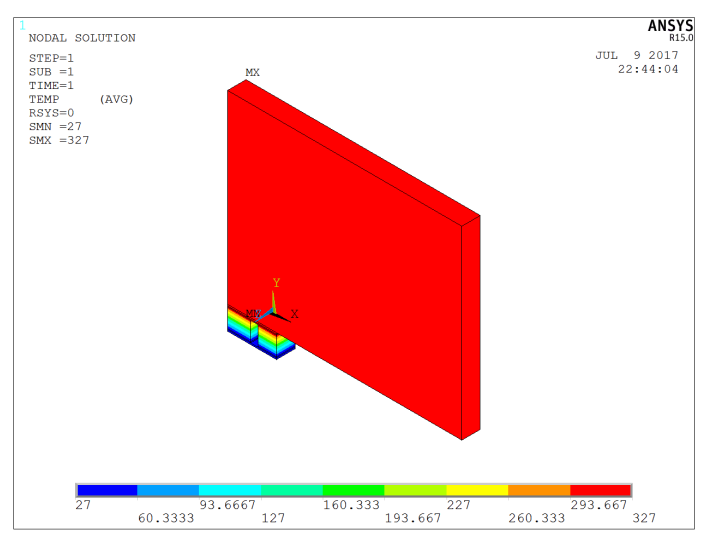

(d)

Fig. 2 Thermal distribution of TEG for (a) design set 1, (b) design set 2, (c) design set 3 , and (d) design set 


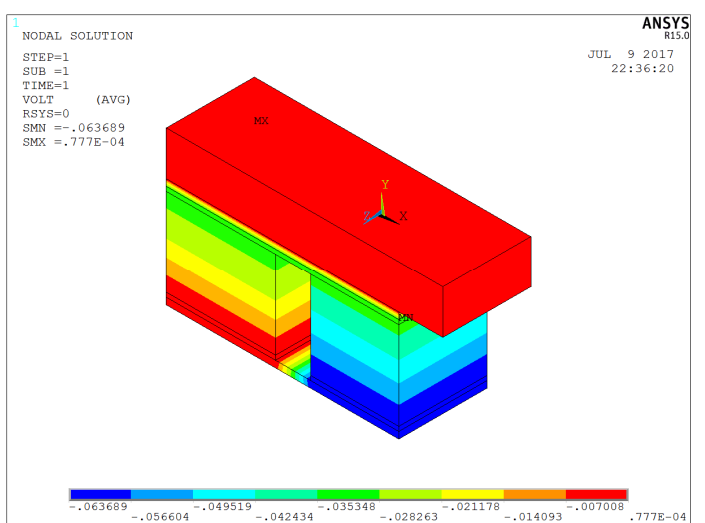

(a)

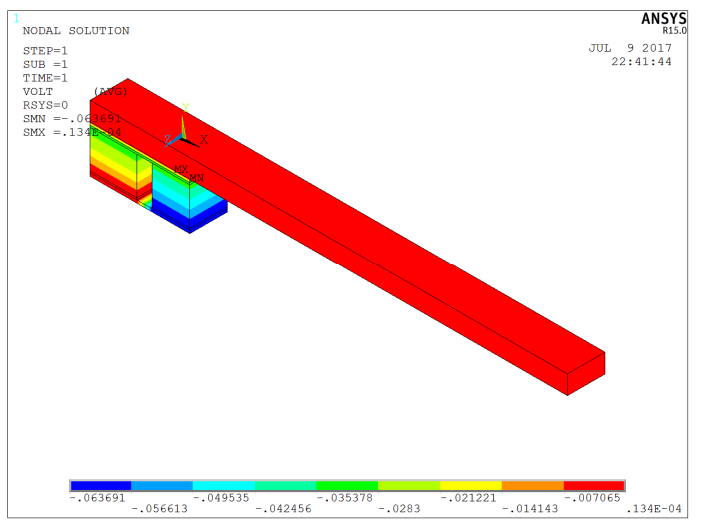

(b)

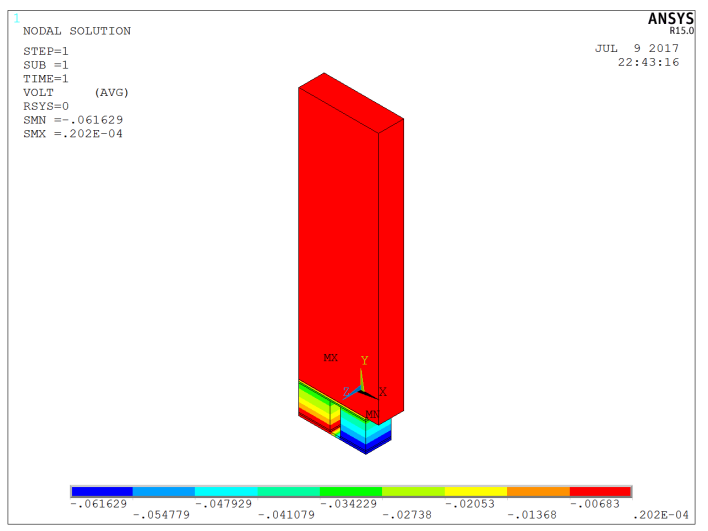

(c)

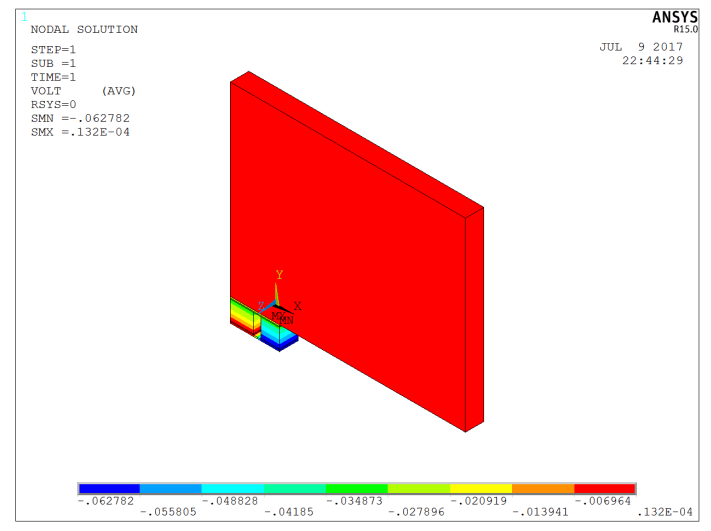

(d)

Fig. 3 Electrical current distribution of TEG for (a) design set 1, (b) design set 2 , (c) design set 3 , and (d) design set 4
In addition, it is known that the alumina ceramic is not a good conductor [17]. Therefore, the drop of temperature between the $\mathrm{Al}$ plates onto the hot side of TEG is due to increment of thermal resistance that occurs inside alumina ceramic plate. Figure 3 shows the electrical current distribution of TEG for each design sets of 1, 2, 3, and 4 .

In Figure 3, the distribution of the electrical current is different with the thermal distribution as shown in Figure 2. This is because TEG material of BiTe has nonlinear and temperature dependent properties compared to that of other materials namely $\mathrm{Al}_{2} \mathrm{O}_{3}$ ceramic, $\mathrm{Cu}$ strip and $\mathrm{Al}$ plate as can be seen in Table 1. In addition TEG material also I built by two different types of $n$ - and p-type BiTe where both materials has different value of impurities and also the reaction towards heat and current flows [19]. In Figure 3 it is noted that the highest current is located at the cold site of n-type BiTe whereas the lowest current is located at p-type BiTe. Figure 4 displays the results obtained in terms of heat rate, electrical current, output power and efficiency.

From Figure 4(c) it is shown that the design set 1 has the highest or optimum value of output power followed by design sets 2,4 , and 3 . The same trend is also shown from the results of heat rate, current and efficiency. Thus it can be inferred that the heat rate, current, power and efficiency has a linear relationship with each other. The reason for this phenomenon is due to the design set 1 has the lowest value of Al plate thickness and width amongst other design sets. This directly increase the heat transfer rate as seen in Figure 3 (a) due to the reduction of thermal resistance experienced by $\mathrm{Al}$ plate. Following is the formula to measure the heat transfer rate [20]:

$$
Q=\frac{\Delta T}{R_{T}}
$$

where $\Delta \mathrm{T}$ is the temperature gradient and $\mathrm{R}_{\mathrm{T}}$ is the total thermal resistance. The result also further support the early observation where the thermal drop between the Al plate and the hot side of TEG is the highest for the case of design set 1 . The lowest output power obtained for the present analysis is design set 3 where it has the highest value of $\mathrm{Al}$ plate thickness and the lowest value of Al plate width. As compared to that of design set 4 with Al plate thickness and width are both have the highest values, design set 3 has the lowest performance even though only $\mathrm{Al}$ plate thickness is increased. One of the reasons that might explain this phenomenon is because of the total thermal resistance, $R_{T}$ experienced by the design set 3 is fully affected through the series connection of thermal resistance as compared to that of design set 4 . Thermal resistance experienced by design set 4 on the other hand, is due to the combined effect of series (thickness of Al plate) and parallel (width of Al plate) connection of thermal resistance. The total thermal resistance is reduced in the series and parallel connection compared to that of solely series connection is due to additional denominator value in the calculation thermal resistance of parallel connection. Hence, the increment of both thickness and width of Al plate can be used to compensate the reduction of performance for the case of $\mathrm{Al}$ plate with higher value of thickness. 


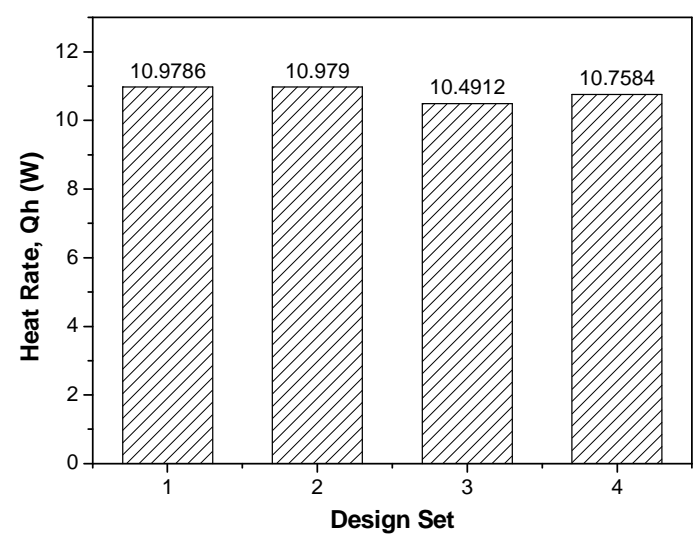

(a)

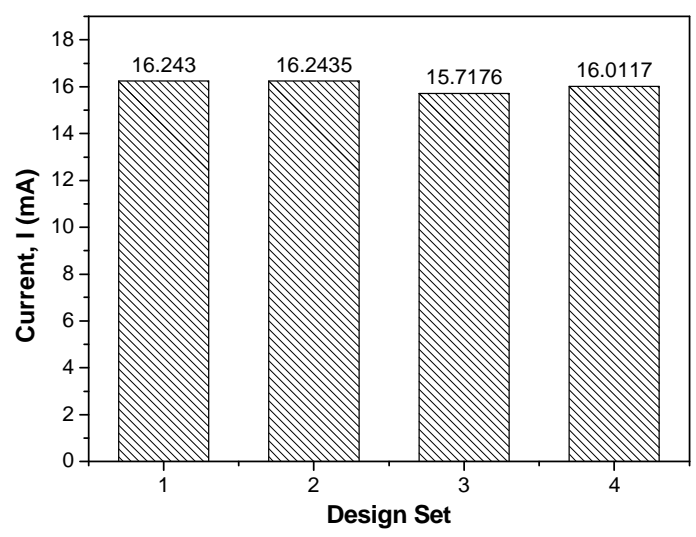

(b)

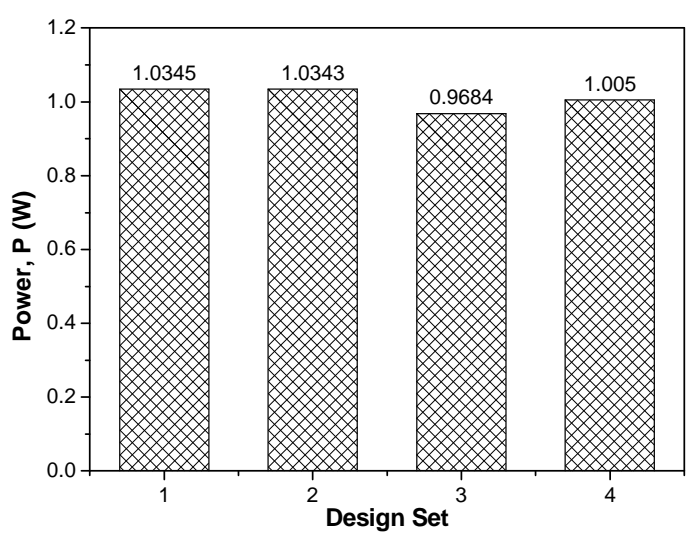

(c)

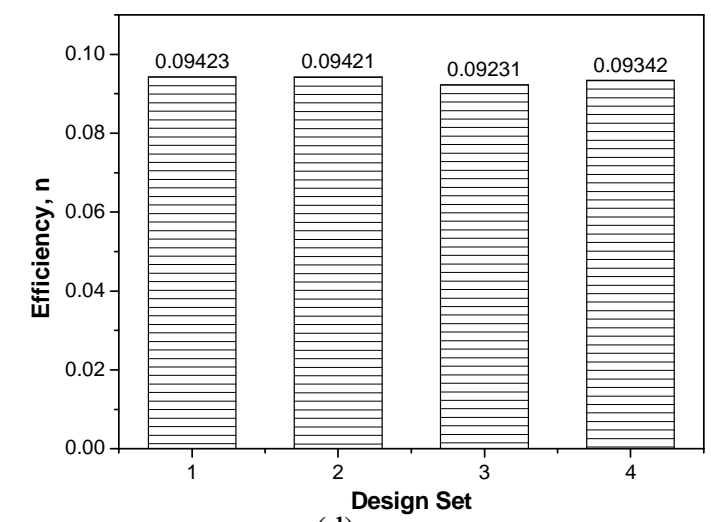

(d)

Fig. 4 Results from finite element analysis; (a) Heat Rate, (b) Current, (c) Power, and (d) Efficiency
The efficiency of the power conversion as shown in Figure 4 (d) also has the same trend as the other graphs in Figure 4. It can be inferred that the efficiency of TEG can be increased if the designed TEG has the highest value of heat transfer rate and highest electrical current. However the efficiency produced by the designed TEG has quite low value ranging from 0.09231 to 0.09423 or $9.23 \% 9.42 \%$ in percentage. TEG is known has lower efficiency compared to that of other power conversion devices. It is because the efficiency of TEG is highly dependent with thermal gradient and the intrinsic parameter of figure of merit (ZT). The value of efficiency around $9 \%$ is considered good especially for the case of TEG made of Bismuth Telluride (BiTe) since the normal efficiency is between $5 \%$ to $6 \%$ [21]. However the higher efficiency value obtained from the finite element analysis is based on the ideal condition as compared to the lower efficiency value obtained from the normal condition where several internal and external power losses might occur.

In order to further identify the sensitivity of the chosen factors (Al thickness and width) and to generate the regression equation of output power generated from proposed TEG, statistical analysis software MINITAB is utilised for the current analysis. Figure 5 shows the pareto chart of the effects of $\mathrm{Al}$ thickness and width factors towards output power.

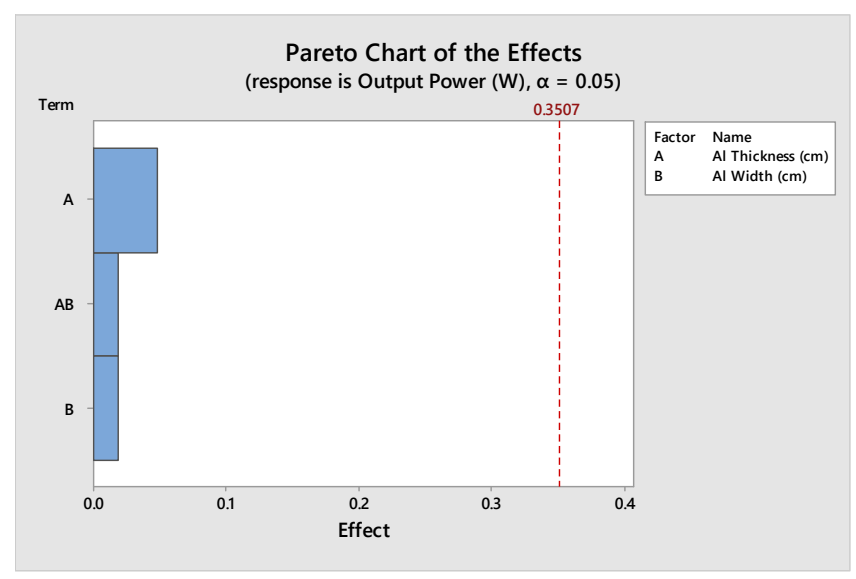

Fig. 5 Pareto Chart of the Effects of Al Thickness and Width Factors towards Output Power

In Figure 5, it is noted that the $\mathrm{Al}$ thickness (A) has the highest sensitivity on changing the TEG output power followed with the cross term of $\mathrm{Al}$ thickness-width (AB) and $\mathrm{Al}$ thickness (B). This result can be used as guidance in developing the prototype of the proposed TEG where the Al thickness is the most sensitive factor in changing the performance of TEG compared to that of $\mathrm{Al}$ width. This finding also suggested that the $\mathrm{Al}$ width can be relaxed on developing the proposed TEG since it has the least effect on the output power. It is known that the development or manufacturing cost of a product can be reduced when the selected factors have the least accuracy tolerance or for this case the least sensitive factor of Al width [22].

MINITAB also generated the linear regression equation or predictive equation for TEG output power. The linear 
regression equation based on full factorial design sets for the proposed TEG is given:

Output Power $=1.038-0.007162(\mathrm{Al}$ Thickness $)-$ 0.000225 (Al Width) + 0.000408 (Al Thickness*Al Width) (7)

The predictive equation (7) is the mathematical representation that useful to get an instant evaluation of the proposed TEG output power. This predictive equation is really helpful especially for those who are building the prototype of the proposed TEG, where the calculated output power can be correlated with the measured data from the prototype. Thus, any discrepancy or offset between the calculation and the measurement can be used to determine the losses that might occur in the practical application of proposed TEG.

\section{CONCLUSION}

The design and modeling process of simple construction of TEG with Al plate is built using finite element analysis (FEA) software of ANSYS. The effect of two factors namely $\mathrm{Al}$ plate thickness and width are analyzed towards the performance of TEG. It is found that the changes of $\mathrm{Al}$ plate thickness and width has different behavior on the thermal and electrical performances of TEG. Based on the design of experiment with full factorial method that has been conducted, it is noted that design set 1 with the lowest value of Al plate thickness and width has the highest or optimum performance of heat rate, current, output power and conversion efficiency. It is noted that the reduction in performance for the design set 3 (with highest value of $\mathrm{Al}$ plate thickness and lowest value of width) can be compensated by increasing the value of $\mathrm{Al}$ plate width as being applied by design set 4 . This is because of the reduction of thermal resistance as shown in design set 4 . The efficiency obtained from the current analysis also has a value of around $9 \%$ as compared to that of normal BeTi alloy based TEG. It is also found that the Al thickness is the most sensitive factor on changing the performance of TEG compared to that of $\mathrm{Al}$ width.

\section{ACKNOWLEDGMENT}

The authors would like to express their gratitude to Universiti Kuala Lumpur (UniKL) for their support and funding under Short Term Grant (Ref. No.: str15001) to realize this research's work.

\section{REFERENCES}

[1] W.Z. Leow, Y.M. Irwan, M. Irwanto, M. Isa, A.R. Amelia, I Safwati, Temperature Distribution of Three-Dimensional Photovoltaic Panel by Using Finite Element Simulation, 6 (2016) 607-612. doi:10.18517/ijaseit.6.5.926.

[2] F.H. Anuwar, A.M. Omar, Future Solar Irradiance Prediction using Least Square Support Vector Machine, 6 (2016) 520-523. doi:10.18517/ijaseit.6.4.899.

[3] G. Fraisse, J. Ramousse, D. Sgorlon, C. Goupil, Comparison of different modeling approaches for thermoelectric elements, Energy $\begin{array}{llll}\text { Convers. } & \text { Manag. } & 65 & \text { (2013) 351-356. }\end{array}$ doi:10.1016/j.enconman.2012.08.022.

[4] L.I. Anatychuk, O.J. Luste, R. V. Kuz, Theoretical and Experimental Study of Thermoelectric Generators for Vehicles, J. Electron. Mater. 40 (2011) 1326-1331. doi:10.1007/s11664-011-1547-7.
[5] S.-K. Kim, B.-C. Won, S.-H. Rhi, S.-H. Kim, J.-H. Yoo, J.-C. Jang, Thermoelectric Power Generation System for Future Hybrid Vehicles Using Hot Exhaust Gas, J. Electron. Mater. 40 (2011) 778783. doi:10.1007/s11664-011-1569-1.

[6] Z. Niu, H. Diao, S. Yu, K. Jiao, Q. Du, G. Shu, Investigation and design optimization of exhaust-based thermoelectric generator system for internal combustion engine, Energy Convers. Manag. 85 (2014) 85-101. doi:10.1016/j.enconman.2014.05.061.

[7] C. Suter, Z.R. Jovanovic, A. Steinfeld, A $1 \mathrm{kWe}$ thermoelectric stack for geothermal power generation - Modeling and geometrical optimization, Appl. Energy. 99 (2012) 379-385. doi:10.1016/j.apenergy.2012.05.033.

[8] H. Xiao, K. Qiu, X. Gou, Q. Ou, A flameless catalytic combustionbased thermoelectric generator for powering electronic instruments on gas pipelines, Appl. Energy. 112 (2013) 1161-1165. doi:10.1016/j.apenergy.2013.01.078.

[9] T.T. Chow, A review on photovoltaic/thermal hybrid solar technology, Appl. Energy. $87 \quad$ (2010) 365-379. doi:10.1016/j.apenergy.2009.06.037.

[10] C. Yu, K.T. Chau, Thermoelectric automotive waste heat energy recovery using maximum power point tracking, Energy Convers. Manag. 50 (2009) 1506-1512. doi:10.1016/j.enconman.2009.02.015.

[11] D.N. Kossyvakis, C.G. Vossou, C.G. Provatidis, E. V. Hristoforou, Computational analysis and performance optimization of a solar thermoelectric generator, Renew. Energy. 81 (2015) 150-161. doi:10.1016/j.renene.2015.03.026.

[12] E.E. Antonova, D.C. Looman, Finite elements for thermoelectric device analysis in ANSYS, in: ICT 2005. 24th Int. Conf. Thermoelectr. 2005., IEEE, 2005: pp. 215-218. doi:10.1109/ICT.2005.1519922.

[13] W.-H. Chen, C.-C. Wang, C.-I. Hung, C.-C. Yang, R.-C. Juang, Modeling and simulation for the design of thermal-concentrated solar thermoelectric generator, Energy. 64 (2014) 287-297. doi:10.1016/j.energy.2013.10.073.

[14] T. Clin, S. Turenne, D. Vasilevskiy, R.A. Masut, Numerical simulation of the thermomechanical behavior of extruded bismuth telluride alloy module, J. Electron. Mater. 38 (2009) 994-1001. doi:10.1007/s11664-009-0756-9.

[15] D.T. Crane, C.R. Koripella, V. Jovovic, Validating steady-state and transient modeling tools for high-power-density thermoelectric generators, J. Electron. Mater. 41 (2012) 1524-1534. doi:10.1007/s11664-012-1955-3.

[16] D.N. Kossyvakis, C.G. Vossou, C.G. Provatidis, E. V. Hristoforou, Computational and experimental analysis of a commercially available Seebeck module, Renew. Energy. 74 (2015) 1-10. doi:10.1016/j.renene.2014.07.024.

[17] U. Erturun, K. Erermis, K. Mossi, Effect of various leg geometries on thermo-mechanical and power generation performance of thermoelectric devices, Appl. Therm. Eng. 73 (2014) 128-141. doi:10.1016/j.applthermaleng.2014.07.027.

[18] D. Ebling, M. Jaegle, M. Bartel, A. Jacquot, H. Böttner, Multiphysics simulation of thermoelectric systems for comparison with experimental device performance, J. Electron. Mater. 38 (2009) 1456-1461. doi:10.1007/s11664-009-0825-0.

[19] S. Turenne, T. Clin, D. Vasilevskiy, R.A. Masut, Finite element thermomechanical modeling of large area thermoelectric generators based on bismuth telluride alloys, J. Electron. Mater. 39 (2010) 1926-1933. doi:10.1007/s11664-009-1049-z.

[20] X. Gou, H. Xiao, S. Yang, Modeling, experimental study and optimization on low-temperature waste heat thermoelectric generator system, Appl. Energy. $87 \quad$ (2010) 3131-3136. doi:10.1016/j.apenergy.2010.02.013.

[21] J.R. Sootsman, D.Y. Chung, M.G. Kanatzidis, New and old concepts in thermoelectric materials., Angew. Chem. Int. Ed. Engl. 48 (2009) 8616-39. doi:10.1002/anie.200900598.

[22] M.N. Zulkifli, Z.A.Z. Jamal, G.A. Quadir, Temperature cycling analysis for ball grid array package using finite element analysis, Microelectron. Int. $28 \quad$ (2011) 17-28. doi:10.1108/13565361111097083. 